\title{
BMJ Open Quality Multipronged intervention for reducing burnout and increasing resiliency in an interdisciplinary care team
}

Heather Bruschwein (iD , ${ }^{1}$ Lucy S Gettle ${ }^{2}$

To cite: Bruschwein $\mathrm{H}$, Gettle LS. Multipronged intervention for reducing burnout and increasing resiliency in an interdisciplinary care team. BMJ Open Quality 2020:9:e001015. doi:10.1136/ bmjoq-2020-001015

Received 10 May 2020 Revised 20 0ctober 2020 Accepted 3 November 2020

Check for updates

(c) Author(s) (or their employer(s)) 2020. Re-use permitted under CC BY-NC. No commercial re-use. See rights and permissions. Published by BMJ.

${ }^{1}$ Department of Psychiatry and Neurobehavioral Sciences, University of Virginia School of Medicine, Charlottesville, Virginia, USA

${ }^{2}$ Department of Nutrition Services, University of Virginia Health System, Charlottesville, Virginia, USA

Correspondence to Dr Heather Bruschwein; hab9z@hscmail.mcc.virginia. edu

\section{INTRODUCTION}

The WHO classifies burnout as a syndrome 'resulting from chronic workplace stress that has not been successfully managed' and characterised by 'feelings of energy depletion or exhaustion; increased mental distance from one's job, or feelings of negativism or cynicism related to one's job; and reduced professional efficacy.' ${ }^{1}$ Burnout is a significant factor in healthcare; it is estimated over half of the physicians experience burnout and the US health system loses US $\$ 4.6$ billion a year in burnout-related turnover and loss of clinical hours. ${ }^{23}$ Resilience, 'the ability to achieve an adequate and positive adjustment to adversity', $(\mathrm{p} 111)^{45}$ has been shown to be a protective factor against burnout and assist employees in continuing to work. ${ }^{46}$ Therefore, effective approaches to reducing burnout and increasing resilience can be of value to healthcare professionals and ultimately healthcare systems. Interventions found to be effective include meditation, ${ }^{7-9}$ mindfulness training, ${ }^{70-12}$ gratitude ${ }^{1314}$ and increasing workflow efficiency. ${ }^{15}$

This programme evaluated the implementation of three interventions designed to reduce burnout and increase resilience among members of an interdisciplinary healthcare team. This team experienced substantial turnover over a year's time, losing 5 of 10 members. There was a need for resiliency strategies for team members in an effort to reduce turnover and enhance professional fulfilment. This report summarises the results of these interventions.

\section{METHODS}

\section{Interventions}

Three distinct interventions were administered to an eight-member interdisciplinary adult cystic fibrosis care team at an academic medical centre during weekly team meetings for 3 months. The first intervention was Three Good Things, an exercise to promote resilience and well-being through the identification of positive aspects of one's day. ${ }^{16}$ Participants were shown a video ${ }^{17}$ explaining the Three Good Things practice and asked to record three good things daily for 2 weeks in journals created by a psychologist and dietitian. For 4 weeks, the team also spent $5 \mathrm{~min}$ at the beginning of each meeting to share a good thing. The second intervention was a presentation by a productivity expert from the institution's human resources department on strategies and tools to work more efficiently with less stress, as decreased productivity is a common symptom of burnout. ${ }^{18}$ The third intervention was a meditation practice led by a psychologist and dietitian. Team members were shown a video on the benefits of meditation, led in a guided meditation and encouraged to use a free 10-day meditation programme on the Headspace app. ${ }^{19}$ In addition, the team implemented a 1 min mindfulness exercise during the meeting for the final 4 weeks of the programme. Patients or members of the public were not involved in the project.

\section{Measures}

Team members were administered the Perceived Stress Scale-10 (PSS-10) ${ }^{20} 21$ and Professional Fulfillment Index (PFI) ${ }^{22}$ surveys prior to and at the end of the 3-month intervention period. The 10-item PSS-10 measures perception of stressful situations by having the respondent rate occurrence of psychological stress on a 5-point scale ranging from 0 ('never') to 4 ('very often'). Responses are summed; higher scores indicate greater psychological stress. PSS-10 population norms are based on probability samples of the US population in 2006 and 2009. ${ }^{23}$ The 16-item PFI comprises professional fulfilment and burnout scores, the latter of which includes work exhaustion and interpersonal disengagement subscores. Two-tailed paired t-tests were used to evaluate whether score differences were statistically significant $(\mathrm{p}<0.05)$. Team members were administered an anonymous five-question survey at the end of the interventional period on the usefulness of the interventions for reducing stress and increasing resiliency and fulfilment at work ('not helpful', 'somewhat helpful' or 'very 


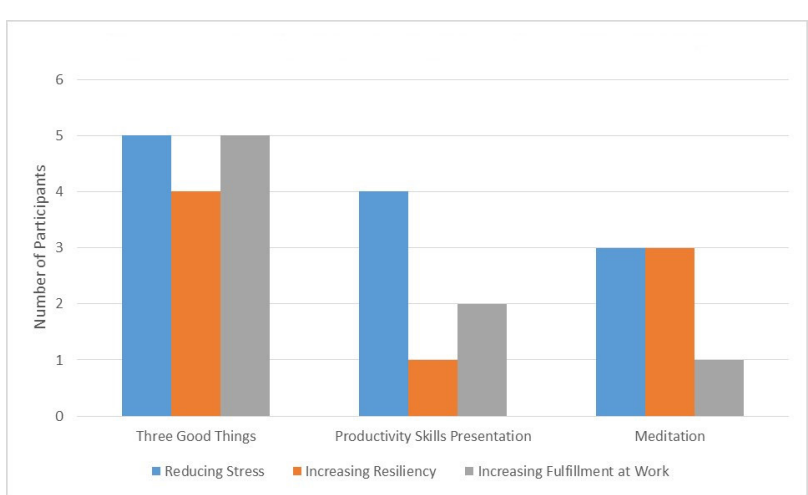

Figure 1 Number of participants rating interventions as 'very helpful'.

helpful'), which intervention was most helpful and which, if any, interventions they planned to use in the future. All measures and surveys were administered via paper and results analysed in Microsoft Excel 2013. Institutional review board approval was waived per the institution's policies.

\section{RESULTS}

At the end of the intervention period, there was a significant decrease in PSS-10 scores. The mean score decreased from the 54th to 36th percentile compared with population normative values $(\mathrm{p}=0.017)$. Of eight team members, seven had a decrease in PSS-10 score. The PFI work exhaustion mean subscore decreased from 5.75 to $4.14(\mathrm{p}=0.030)$ and there was a non-significant decrease in the mean burnout subscore from 9.00 to 6.57 ( $\mathrm{p}=0.106)$. There was no difference in professional fulfilment and interpersonal disengagement subscores. All team members completed the post intervention survey. At least one person rated each intervention as 'very helpful' for reducing stress, increasing resiliency and/or increasing fulfilment at work (figure 1). Three Good Things received the most 'very helpful' ratings (figure 1). Overall, three team members selected Three Good Things as the most helpful intervention, two selected the productivity skills presentation and one selected meditation. For each intervention, four of eight team members indicated they planned to use the intervention again.

Team member retention increased from 5 of $10(50 \%)$ in 2017 to 9 of 10 (90\%) in 2018, the year of programme implementation. The subsequent annual retention rate in 2019 was 8 of $10(80 \%)$.

\section{DISCUSSION}

Previous studies have identified effective interventions to reduce burnout and improve resiliency, including meditation, ${ }^{7-9}$ mindfulness training, ${ }^{70-12}$ gratitude $^{13}{ }^{14}$ and increasing workflow efficiency. ${ }^{15}$ Consistent with these findings, this multipronged approach to reduce burnout and increase resiliency contributed to a significant decrease in team member stress and work exhaustion scores over a 3-month period. Of the three interventions, more team members reported Three Good Things as most helpful. All interventions were found to be 'very helpful' by at least one team member. Therefore, it may be prudent to consider multipronged approaches to decrease burnout and increase resiliency, as individuals may respond differently to interventions.

Limitations include small sample size and survey administration timing. Independent effects of each intervention may be better understood if survey administration occurred throughout the programme rather than preintervention and postintervention. Future research should include larger sample sizes and increased measurement between interventions.

\section{CONCLUSION}

Burnout is a critical issue in healthcare. A multipronged approach may be useful to decrease burnout and increase resiliency in team members. These interventions may provide teams with inexpensive, easy to implement and sustainable options for promoting resilience.

Acknowledgements The authors would like to thank the University of Virginia interdisciplinary adult cystic fibrosis team for their participation in this program, Dr Dana Albon for her support of this program and her mentorship, Marne Power of the University of Virginia Human Resources Department for her presentation on productivity, and the Cystic Fibrosis Learning Network for introducing the concept of Joy at Work to the authors.

Contributors Both HB and LSG planned the program, performed data collection, conducted data analysis, drafted the manuscript, critically reviewed the manuscript and approved the final version.

Funding The authors have not declared a specific grant for this research from any funding agency in the public, commercial or not-for-profit sectors.

Competing interests None declared.

Patient and public involvement Patients and/or the public were not involved in the design, or conduct, or reporting, or dissemination plans of this research.

Patient consent for publication Not required.

Provenance and peer review Not commissioned; externally peer reviewed.

Open access This is an open access article distributed in accordance with the Creative Commons Attribution Non Commercial (CC BY-NC 4.0) license, which permits others to distribute, remix, adapt, build upon this work non-commercially, and license their derivative works on different terms, provided the original work is properly cited, appropriate credit is given, any changes made indicated, and the use is non-commercial. See: http://creativecommons.org/licenses/by-nc/4.0/.

ORCID iD

Heather Bruschwein http://orcid.org/0000-0003-1180-5149

\section{REFERENCES}

1 World Health Organization. Burn-out an "occupational phenomenon": international classification of diseases. Available: https://www.who. int/mental_health/evidence/burn-out/en/ [Accessed 15 Oct 2020].

2 Shanafelt TD, Hasan O, Dyrbye LN, et al. Changes in burnout and satisfaction with work-life balance in physicians and the general us working population between 2011 and 2014. Mayo Clin Proc 2015;90:1600-13.

3 Han S, Shanafelt TD, Sinsky CA, et al. Estimating the attributable cost of physician burnout in the United States. Ann Intern Med 2019;170:784-90.

4 Arrogante O, Aparicio-Zaldivar E. Burnout and health among critical care professionals: the mediational role of resilience. Intensive Crit Care Nurs 2017;42:110-5.

5 Fletcher D, Sarkar M. Psychological resilience: a review and critique of definitions, concepts, and theory. Eur Psycho/2013.

6 Guo Y-F, Luo Y-H, Lam L, et al. Burnout and its association with resilience in nurses: a cross-sectional study. J Clin Nurs 2018;27:441-9. 
7 Yates SW. Physician stress and burnout. Am J Med 2020;133:160-4.

8 Thimmapuram JR, Grim R, Bell T, et al. Factors influencing work-life balance in physicians and advance practice clinicians and the effect of Heartfulness meditation conference on burnout. Glob Adv Health Med 2019;8:216495611882105.

9 Goyal M, Singh S, Sibinga EMS, et al. Meditation programs for psychological stress and well-being: a systematic review and metaanalysis. JAMA Intern Med 2014;174:357-68.

10 van Wietmarschen $\mathrm{H}$, Tjaden $\mathrm{B}$, van Vliet $\mathrm{M}$, et al. Effects of mindfulness training on perceived stress, self-compassion, and selfreflection of primary care physicians: a mixed-methods study. BJGP Open 2018;2:bjgpopen18X101621.

11 Gauthier T, Meyer RML, Grefe D, et al. An on-the-job mindfulnessbased intervention for pediatric ICU nurses: a pilot. J Pediatr Nurs 2015;30:402-9.

12 Goodman MJ, Schorling JB. A mindfulness course decreases burnout and improves well-being among healthcare providers. Int $J$ Psychiatry Med 2012;43:119-28.

13 Tawfik DS, Sexton JB, Adair KC, et al. Context in quality of care: improving teamwork and resilience. Clin Perinatol 2017;44:541-52.

14 Lee J-Y, Kim S-Y, Bae K-Y, et al. The association of gratitude with perceived stress and burnout among male firefighters in Korea. Pers Individ Dif 2018;123:205-8.

15 Bohman B, Dyrbye L, Sinsky C, et al. Physician well-being: the reciprocity of practice efficiency, culture of wellness, and personal resilience. NEJM Catal 2017.
16 Rippstein-Leuenberger K, Mauthner O, Bryan Sexton J, Sexton JB, et al. A qualitative analysis of the three good things intervention in healthcare workers. BMJ Open 2017;7:e015826.

17 Texas Children's Hospital. Dr. J. Bryan Sexton - three good things [video on the Internet], 2012. Available: https://www.youtube.com/ watch?v=hZ4aT_RVHCs

18 Askey-Jones R. Mindfulness-based cognitive therapy: an efficacy study for mental health care staff. J Psychiatr Ment Health Nurs 2018;25:380-9.

19 iTunes. Headspace [Mobile application software]. Headspace Inc (Version 3.119), 2018. Available: http://itunes.apple.com

20 Cohen S, Kamarck T, Mermelstein R. A global measure of perceived stress. J Health Soc Behav 1983;24:385-96.

21 Cohen S, Williamson G. Perceived stress in a probability sample of the United States. In: Spacapan S, Oskamp S, eds. The Claremont Symposium on applied social psychology. the social psychology of health. Newbury Park, CA: Sage, 1988: 31-67.

22 Trockel M, Bohman B, Lesure E, et al. A brief instrument to assess both burnout and professional fulfillment in physicians: reliability and validity, including correlation with self-reported medical errors, in a sample of resident and practicing physicians. Acad Psychiatry 2018;42:11-24

23 Cohen S, Janicki-Deverts D. Who's stressed? distributions of psychological stress in the United States in probability samples from 1983, 2006, and 20091. J Appl Soc Psychol 2012;42:1320-34. 